REVISTA EVIDENCIAÇÃO CONTÁBIL \& FINANÇAS

João Pessoa, v. 4, n. 3, p. 72-88, set./dez. 2016.

ISSN 2318-1001

DOI: 10.18405/recfin20160305

Disponível em: http://periodicos.ufpb.br/ojs2/index.php/recfin

\title{
ANÁLISE QUANTO AO USO DE FERRAMENTAS E INFORMAÇÕES GERENCIAIS PELOS PRODUTORES DE GADO DE CORTE ${ }^{1}$
}

\author{
ANALYSIS ON THE USE OF TOOLS AND INFORMATION \\ MANAGEMENT FOR BEEF CATTLE PRODUCERS
}

\author{
Marcelino Franco Moura ${ }^{2}$ \\ Mestre em Ciências Contábeis pela Universidade Federal de Uberlândia (UFU) \\ Professor do Instituto Federal de Educação, Ciência e Tecnologia do Triângulo Mineiro (IFTM) \\ marcelino@iftm.edu.br \\ Nevison Amorim Pereira \\ Mestre em Ciências Contábeis pela Universidade Federal de Uberlândia (UFU) \\ nevisonpm@yahoo.com.br \\ Ilírio José Rech \\ Doutor em Controladoria e Contabilidade pela USP \\ Professor do Programa de Pós-Graduação em Ciências Contábeis da UFU \\ ilirio@facic.ufu.br
}

\begin{abstract}
RESUMO
Diante da importância da pecuária de corte na economia nacional e das informações para a tomada de decisão, o presente estudo teve como objetivo verificar o uso de ferramentas e informações gerenciais por produtores rurais, identificando os fatores que motivam os mesmos a utilizarem estas ferramentas no direcionamento e planejamento de seu negócio. Trata-se de uma pesquisa qualitativa, descritiva e os dados foram coletados por meio de questionário aplicado a 30 produtores rurais criadores de gado de corte, na cidade de Ituiutaba, situada na região do Triângulo Mineiro. Os resultados evidenciam que os produtores rurais, de um modo geral, utilizam algumas informações gerenciais informais para a manutenção ou controle de sua produção. Também se detectou uma limitação em adotar a contabilidade e suas informações formais como ferramenta gerencial e de controle. Na percepção dos produtores de gado, as informações contábeis só são consideradas relevantes quando se trata de questões referentes ao fisco/imposto de renda.
\end{abstract}

Palavras-chave: Agronegócio; Pecuária de Corte; Informações Gerenciais; Tomada de Decisão.

\section{ABSTRACT}

Given the importance of beef cattle in the national economy and information for decision making, this study aimed to verify the use of management tools and information for farmers, identifying the

\footnotetext{
${ }^{1}$ Artigo recebido em: 17/05/2016. Revisado por pares em: 19/08/2016. Versão final recebida em: 05/09/2016. Recomendado para publicação em: 07/09/2016 por Luiz Felipe de Araújo Pontes Girão (Editor Adjunto). Publicado em: 28/10/2016. Organização responsável pelo periódico: UFPB.

${ }^{2}$ Endereço: Instituto Federal do Triângulo Mineiro, Rua Belarmino Vilela Junqueira, s/n, Novo Tempo II, CEP 38.300-970, Ituiutaba/MG.

DOI: $\underline{\text { http://dx.doi.org/10.18405/recfin20160305 }}$
} 
factors that motivate them to use these tools in targeting and planning your business. It is a qualitative, descriptive research and data were collected through a questionnaire applied to 30 farmers beef cattle breeders in the city of Ituiutaba, located in the Triangulo Mineiro region. The results show that farmers, in general, use some informal management information for maintenance or control of production. Also, detected a limitation to adopt accounting and its formal information as a management and control tool. In the perception of livestock producers, accounting information is only considered relevant when it comes to issues related to revenue/income tax.

Keywords: Agribusiness; Beef Cattle; Management Information; Decision Taking.

\section{INTRODUÇÃO}

No ambiente do agronegócio há diversos empreendimentos, desde grandes organizações sólidas e eficientes (quanto ao aspecto de seus controles) até negócios de pequeno ou médio porte (frequentemente de administração familiar), que ainda se observa uma ausência ou sensível inadequação de controles contábeis e informações gerenciais de suporte à gestão.

Em toda organização produtiva, a interpretação das informações processadas é fator decisivo. Francischetti Junior e Zanchet (2006) relatam que as informações fornecidas pela contabilidade constituem um sistema de grande utilidade no processo de tomada de decisão nas empresas do ramo do agronegócio e desempenham papel importante sob a forma de ferramenta gerencial à disposição dos produtores rurais. Por sua vez, os produtores rurais, constituídos em empresas agropecuárias, atuam em sua maioria como proprietário e também como gestor, deixando em alguns casos de observar os princípios e normas contábeis da entidade, miscigenando os gastos da família ao da empresa, o que pode prejudicar o resultado esperado de sua produção (MARION, 1996).

O capital de uma propriedade agropecuária necessita ter uma administração condizente com sua realidade e buscar informações precisas para seu desempenho. Nesse sentido,

\footnotetext{
Administrar uma atividade agropecuária requer ampla abrangência de informações em termos de desempenho físico e financeiro. Algumas vezes, entretanto, muitas das informações necessárias são registradas apenas na memória de quem administra ou em anotações informais (MARION, 1996, p. 19).
}

Todavia, a maioria dos proprietários rurais não conhece a importância da contabilidade para seus negócios, sendo que a mesma é essencial para auxiliá-los na obtenção de uma maior rentabilidade (VIANA; COSTA; SANTOS, 2014).

No âmbito do agronegócio, destaca-se a atividade de pecuária, pois de acordo com Pereira, Oliveira e Barbalho (2007) o Brasil possui o maior rebanho comercial do mundo e está entre os maiores exportadores de carne. Ressaltam também os investimentos em tecnologia, as modernas técnicas de manejo do rebanho e o controle sanitário feito pelos pecuaristas visando garantir qualidade ao produto em virtude da competitividade. Nesse ambiente competitivo, pressupõe-se que a informação seja exigida em todo seu potencial de complexidade, considerando que as modernas práticas de gestão requerem decisões baseadas em fatos e dados (SOUZA, 2004).

Devido à importância desse setor, há necessidade de técnicas e processos contábeis para apoiar e sustentar o negócio. Portanto, surge a questão motivadora da presente pesquisa: qual a intensidade do uso das ferramentas gerenciais por produtores de gado de corte no gerenciamento de seu negócio e na tomada de decisão? Sendo assim, este estudo tem como objetivo geral verificar o uso de ferramentas e informações gerenciais pelos produtores de gado de corte na administração de seu negócio.

No levantamento bibliográfico, no ramo do agronegócio, foram encontrados diversos estudos com base no uso e na aplicabilidade dos instrumentos contábeis, econômicos, demonstrações 
financeiras e na tomada de decisão. Entre eles, podem-se citar os trabalhos de Cook e Chaddad (2000), Souza (2009), Ali e Kumar (2011), Hofer et al. (2011), Vestena et al. (2011), Korutaro e Biekpe (2013) e Barnes et al. (2013).

O estudo encontra justificativa em Souza (2004, p. 22), haja vista que "o gerenciamento das empresas de pecuária, apesar da sua importância social e econômica, tem recebido pouca atenção por parte dos estudiosos da área contábil". A pesquisa é delimitada, por conveniência, ao universo dos criadores de pecuária bovina filiados ao sindicato rural da cidade de Ituiutaba, localizada no Estado de Minas Gerais. O presente estudo está organizado, além desta introdução, da seguinte forma: uma seção para abordar os referenciais teóricos sobre o agronegócio e o envolvimento das informações gerenciais no espaço rural; posteriormente são apresentados os aspectos metodológicos e as análises de resultados obtidos por meio da pesquisa empírica. E, finalmente, as considerações finais.

\section{REFERENCIAL TEÓRICO}

Fundamentado na literatura contábil do setor de agronegócio, o estudo faz uma abordagem teórica sobre os principais temas apresentados neste estudo.

\subsection{Agronegócio: Suas Definições e Características Peculiares}

Davis e Goldberg (1957) definiram o conceito de agronegócio como a soma total de todas as operações envolvidas na fabricação e distribuição de insumos agrícolas; as operações de produção dentro da unidade agrícola; o armazenamento, processamento e distribuição de produtos agrícolas e dos itens produzidos a partir deles. Portanto, o agronegócio engloba atividades relacionadas a insumos para a agricultura, a produção agrícola; agroindustrialização dos produtos primários; transporte e comercialização de produtos primários e processados (CONTINI, 2001).

Já para Callado e Callado (2006), o agronegócio é o conjunto de empresas caracterizadas pela produção de insumos agrícolas, manutenção de propriedades rurais com a criação de gado, processamento de produtos agropecuários e até a distribuição de toda a produção. Corroborando com esse entendimento, o termo agronegócio é aplicado a três grandes grupos, conforme Marion (2006): a agricultura (produção vegetal), que inclui o cultivo de cereais, hortaliças, tubérculos, fibras e mais uma infinidade de produtos vegetais; a atividade zootécnica (produção animal); e, por fim, o segmento das agroindústrias (indústrias rurais), que abrange as organizações que se dedicam ao beneficiamento de produtos agrícolas, transformação de produtos zootécnicos ou agrícolas em geral.

No início da década de 1980, o Brasil era apenas um importador de alimentos; já neste segundo milênio a realidade se reverteu e é considerado o maior exportador de carne bovina, aves, cana de açúcar, etanol e o segundo maior exportador de soja, após os Estados Unidos da América (CONNOLLY, CONNOLLY e LYONS, 2012). Essa expansão permitiu ao agronegócio aumentar a sua participação no Produto Interno Bruto (PIB), e nas últimas décadas, o agronegócio tem crescido em nível mundial representando parte importante da economia de alguns países (CALSINA, 2012). O agronegócio, de uma forma abrangente, cresceu consideravelmente no acumulado de janeiro a abril de 2013, com um aumento de 2,99\% no PIB do respectivo setor e isto se deve à expansão da agropecuária, que apresentou uma expansão de 5,01\% no $1^{\circ}$ quadrimestre de 2013 (CNPC, 2013).

Com o crescimento do agronegócio torna-se necessário um maior controle gerencial pelos produtores, uma tomada de decisão planejada para obter maior produtividade, rentabilidade e lucratividade (BATALHA, 2008). Ainda, segundo o autor, as organizações, em um ambiente globalizado, competitivo e instável economicamente, necessitam melhorar o seu desempenho, mas para isto o agronegócio necessita de mecanismos gerenciais que lhe permita exercer um controle nas suas atividades para fazer face à competitividade. 
Um dos problemas do setor é gerar informações gerenciais para a tomada de decisão, mas o sucesso da empresa rural está relacionado ao seu grau de gerenciamento, com habilidade técnica e administrativa para o aproveitamento racional dos recursos à sua disposição (SANTOS; MARION, 1993; CARVALHO; FIÚZA; LOPES, 2008). Nesse sentido, Hutchings e Nordblom (2011) dizem que as empresas agrícolas bem-sucedidas têm características comuns, tais como escala, baixos custos e técnicas de gestão adequadas, que geram excedentes maiores. Contudo, os agricultores e pecuaristas ainda enfrentam grandes dificuldades quanto à política agrícola nacional e o apoio eficiente do governo em financiamentos e comercialização da safra; muitos destes problemas são amenizados ou até mesmo resolvidos através de algumas ferramentas gerenciais e/ou administrativas que favorecem no controle financeiro e na tomada de decisões (BATALHA, 2008).

\subsection{Contabilidade Rural e a Contabilidade da Pecuária}

"A Contabilidade é um processo sistemático de mensuração e evidenciação a vários usuários, de informações financeiras relevantes para os tomadores de decisões a respeito das atividades econômicas de uma organização ou entidade" (SALMONSON, 1977 apud MARION, 2006, p. 1). Sá (2008, p. 42) define Contabilidade como "a ciência que estuda os fenômenos patrimoniais, preocupando-se com a realidade, evidências e comportamento dos mesmos, em relação à eficácia funcional das células sociais".

Diante das definições de contabilidade, pode-se dizer que seu objetivo é servir-se de ferramentas para avaliação das empresas e de seus gestores, prestação de contas da gestão realizada e informações para o fornecimento de insumos necessários aos seus usuários para tomada de decisões (RIBEIRO FILHO; LOPES; PEDERNEIRAS, 2009). A contabilidade, de forma sistemática, pode atuar em diferentes setores, de modo geral ou particular (certos setores da empresa). Contudo,

\footnotetext{
Quando estudada de forma genérica, a Contabilidade é denominada Contabilidade Geral ou Contabilidade Financeira. Quando aplicada a um ramo específico, normalmente é denominada de acordo com a atividade daquele ramo. Diante destas especificidades e do estudo em questão, surge a contabilidade rural (MARION, 2006, p. 25).
}

Complementando a fundamentação de Marion (2006), Crepaldi (2012) relata que a contabilidade rural é um instrumento administrativo que, através de suas ferramentas, pode controlar o patrimônio das empresas rurais e mensurar os resultados prestando informações sobre o seu patrimônio e o resultado das organizações rurais. O produtor rural, assim como qualquer outro empresário ou investidor, necessita de informações precisas e coerentes para a tomada de decisão. A contabilidade, em sua particularidade, serve como elemento essencial para tal fornecimento de informações necessárias à gestão de um produtor rural (BATALHA, 2008).

A contabilidade pecuária refere-se à criação de animais que vivem em coletividade, podendo ser bovinos, bubalinos, ovinos e aves. A pecuária bovina pode ser dividida em leiteira e de corte. A pecuária de corte tem objetivo de produção de carne para consumo, enquanto a leiteira, é destinada à produção de leite e seus derivados (VIANA; COSTA; SANTOS, 2014). Segundo Marion (2006, p. 106), "no Brasil, em termos de Contabilidade da Pecuária, há dois tipos de avaliação do estoque vivo (plantel): valores de custo e valores de mercado".

Já Lemes (1996) identifica duas classificações básicas necessárias para entendimento do fluxo contábil na atividade pecuária: i) ativo circulante - estoque - gado que será comercializado ou consumido sob a forma de bezerro, novilho magro ou novilho gordo; ii) ativo permanente imobilizado - gado destinado à reprodução (reprodutor - touro ou matriz-vaca). Traçando um paralelo com a indústria, Lemes (1996, p. 38) ainda enfatiza: “Na pecuária, o gado reprodutor tem a 
função semelhante a máquinas e equipamentos industriais, e o rebanho em formação seria o produto em elaboração de uma indústria (estoque)".

Para a classificação no balanço patrimonial e melhor entendimento da contabilidade da pecuária, é imprescindível compreender que na atividade de pecuária de corte, há três fases distintas que os animais passam até o abate: $1^{\circ}$ ) cria (produção de bezerros a serem vendidos após o desmame); $2^{o}$ ) recria (a partir do bezerro adquirido, a produção, venda do novilho para engorda); $3^{\text {o) }}$ engorda (a partir do novilho magro, a produção e a venda do novilho gordo) (MARION, 2006).

A contabilidade rural, especificamente a de pecuária, necessita obter informações e relatórios que auxiliem nas três fases citadas anteriormente, diante do processo decisório de investimento e produção. A seguir, é apresentado um exemplo de determinado evento que pode utilizar de relatórios e informações gerenciais para um processo decisório e de controle patrimonial,

[...] por um lado, um nascimento de um bezerro representará acréscimo patrimonial, ganho econômico; por outro lado, a morte de um bezerro, ou novilho, ou qualquer outro animal significa redução (perda) do patrimônio, devendo ser subtraída dos ganhos para se apurar o valor líquido (MARION, 2006, p. 115).

Viana, Costa e Santos (2014) destacam que as empresas que lidam com gado têm um ciclo operacional geralmente maior que um ano. Isto porque o gado leva um período de tempo maior que um ano para nascer, crescer e estar com tamanho ideal para o abate. Diante desse ciclo maior, ter a informação em tempo real do custo que se tem, torna-se uma ferramenta de suma importância à administração, determinando a melhor hora para vender o rebanho, não deixando assim os custos serem maiores que o ganho de peso, e nem manter o rebanho se o preço de mercado está baixo (VIANA; COSTA; SANTOS, 2014).

Kitagawa e Sornberger (2010) realçam que em se tratando de pecuária de corte, é necessário um controle formal do número de cabeças de gado, pois a partir destes controles, poderão realizados cálculos que auxiliarão o produtor a conhecer o custo real dos animais de sua propriedade e ao melhor momento de venda. E quando se fala em redução do patrimônio, saída de capital, subtração de ganhos, acréscimos e ganhos econômicos, é por meio das informações contábeis e gerenciais que se podem receber estes dados e tomar as melhores decisões. Assim, cabe ao sistema da contabilidade gerencial se adequar para que os gestores possam criar as melhores estratégias empresariais possíveis, o que será relatado no item a seguir.

\subsection{Contabilidade Gerencial e a Informação Contábil na Tomada de Decisão}

Para Batalha (2008), o produtor rural é livre para adotar as melhores estratégias comerciais em suas atividades rurais, assim como controlar seus recursos em diferentes segmentos da produção, de forma a utilizar os fatores de produção da maneira mais adequada. "O produtor deve estar sintonizado com as tendências do mercado que, de alguma forma, afetam seu segmento, e também com as possíveis mudanças que possam vir a ocorrer numa esfera mais distante" (BATALHA, 2008, p. 493-494). Cabe à contabilidade gerencial dar relevância às técnicas e aos procedimentos contábeis e gerenciais que deem uma perspectiva de sucesso para as empresas, ou seja,

A contabilidade gerencial pode ser caracterizada, superficialmente, como um enfoque especial conferido a várias técnicas e procedimentos contábeis já conhecidos e tratados na contabilidade financeira, na contabilidade de custos, na análise financeira e de balanços etc., colocados numa perspectiva diferente, num grau de detalhe mais analítico ou numa forma de apresentação e classificação diferenciada, de maneira a auxiliar os gerentes das entidades em seu processo decisório (IUDÍCIBUS, 2006, p. 21). 
Não é uma separação da contabilidade rural e da contabilidade gerencial e sim, a atuação da contabilidade gerencial na contabilidade rural. A contabilidade gerencial, trará de certa forma informações contábeis que permitirão uma tomada de decisão precisa e com um alto grau de acerto na otimização de resultados, em conformidade com o objetivo empresarial.

Consoante Horngren, Sundem e Stratton (2004, p. 4), “o objetivo básico da informação contábil é ajudar alguém a tomar decisões (...) independentemente de quem está tomando a decisão, sendo que o entendimento da informação contábil propicia a tomada de decisão melhor e mais bem fundamentada". Ainda segundo os autores anteriores, uma informação contábil coerente contribui em atingir objetivos e metas de um ramo de atividade e a esclarecer questões de: registro (acumulação e classificação dos dados para avaliar o desempenho organizacional); direção de atenção (relato e interpretação de informações em relatórios contábeis que auxiliam os gestores a encontrar problemas, ineficiências e oportunidades) e solução de problemas (quantificação de resultados prováveis advindos de ações e escolha do melhor caminho a seguir).

Corroborando com Horngren, Sundem e Stratton (2004), Padoveze (2008) destaca que a informação contábil deve ser útil e segura para os gestores de uma entidade, principalmente para os que buscam a excelência empresarial, inclusive para conseguir adquiri-las a um custo favorável e a aceitável pela entidade. Horngren, Sundem e Stratton (2004, p. 194), em razão das alternativas de ação, discorrem sobre o envolvimento da tomada de decisão e dizem que "a tomada de decisão da gestão envolve a comparação de dois ou mais cursos alternativos de ação (...) quando há mais de dois cursos alternativos de ação, os gestores frequentemente comparam uma ação em particular contra o conjunto inteiro de alternativas".

Portanto, no estudo das decisões tomadas pelos usuários, bem como do impacto dessas decisões sobre o fornecimento de informações, os teóricos da contabilidade têm adotado duas estratégias: perguntar como as pessoas tomam as decisões (enfoque normativo) e perguntar como as pessoas realmente tomam as decisões (enfoque positivo) (HENDRIKSEN; VAN BREDA, 1999).

\section{METODOLOGIA}

A pesquisa é um processo formal e sistemático, em busca da construção de novos conhecimentos, podendo corroborar ou refutar conhecimentos já existentes (THIOLLENT, 1997).

\subsection{Caracterização Quanto ao Objetivo}

Quanto aos objetivos propostos, a pesquisa é de natureza descritiva, com registros, análises e descrições de dados coletados por meio de uma pesquisa de campo - entrevista estruturada. Segundo Gil (1999), a pesquisa descritiva tem o intuito de descrever as características de um evento ou de uma população na tentativa de utilizar de técnicas de coletas de dados, para identificar, relatar, analisar, comparar e compreender eventos e resultados.

\subsection{Caracterização Quanto aos Procedimentos}

Quanto aos procedimentos, a pesquisa é de levantamento (survey) e bibliográfica. Para Gil (1999), os estudos de levantamento são normalmente utilizados em estudos descritivos e relevantemente úteis e aplicáveis em pesquisas de opinião e atitude. Segundo Beuren (2012), a pesquisa bibliográfica deve ser feita em todo o referencial já existente e de domínio público em relação ao tema estudado, desde publicações avulsas, a jornais, teses, dissertações, revistas científicas, artigos científicos. Ainda com relação à pesquisa bibliográfica,

No que diz respeito a estudos contábeis, percebe-se que a pesquisa bibliográfica está sempre presente, seja como parte integrante de outro tipo de pesquisa ou exclusivamente enquanto 
delineamento. [...] podem ajudar o estudante a conhecer o que foi produzido de importante sobre o objeto da pesquisa (BEUREN, 2012, p. 87).

Assim, foram pesquisados trabalhos relacionados com o agronegócio e com a informação contábil na pecuária.

\subsection{Caracterização Quanto à Abordagem do Problema}

Quanto à abordagem, a pesquisa é de natureza qualitativa, pois foram abordadas suas conceituações teóricas frente à contabilidade como instrumento de tomada de decisão, especificamente no ramo da criação de gado de corte. Além disso, não foi empregada nenhuma técnica estatística específica para avaliação dos dados, sendo considerados somente os percentuais referentes a cada resposta do questionário aplicado.

\footnotetext{
Na contabilidade, é bastante comum o uso da abordagem qualitativa como tipologia de pesquisa. Cabe lembrar que, apesar de a Contabilidade lidar intensamente com números, ela é uma ciência social, e não uma ciência exata como alguns poderiam pensar, o que justifica a relevância do uso da abordagem qualitativa (BEUREN, 2012, p. 92).
}

Neste aspecto, Richardson (1999, p. 80) relata que "os estudos que empregam uma metodologia qualitativa podem descrever a complexidade de determinado problema, analisar a interação de certas variáveis, compreender e classificar processos dinâmicos vividos por grupos sociais".

\subsection{Coleta, Análise e Interpretação dos Dados}

Quanto à coleta de dados, foi utilizado como instrumento um questionário, com uma série ordenada de dezenove perguntas fechadas. Nas questões de 7 a 16, com exceção da 15, aceitou-se marcar mais de uma opção, em virtude das multiplicidades de determinadas informações e ações gerenciais que poderiam ser respondidas. Segundo Beuren (2012), o processo de elaboração do questionário requer perguntas claras e objetivas, assim como conhecer o objeto de pesquisa em questão, podendo ser perguntas de respostas abertas ou fechadas.

As perguntas foram elaboradas e adaptadas com base nas pesquisas feitas por Hofer et al. (2011), Vestena et al. (2011) e Marion (1996), que analisaram a relevância do controle contábil no desenvolvimento do agronegócio e a utilização das ferramentas contábeis e gerenciais no controle financeiro no ramo do agronegócio. Inicialmente, foi realizado um pré-teste com dois produtores rurais para avaliar a compreensão, a objetividade, a precisão e a exatidão do roteiro estruturado do entrevistado, de forma a validar o questionário. A validação do conteúdo é uma propriedade fundamental na medida de um constructo, evitando falhas de medidas, que podem ser reduzidas quando os pesquisadores reportam de forma adequada o conteúdo (SCHREISHEIM et al., 1993).

Após a realização do pré-teste, foram feitos ajustes no tratamento da coleta da informação, quanto ao nível de detalhamento das questões, quantidade de questões e forma de apresentação do questionário (somente frente). Em seguida, o questionário foi aplicado a trinta produtores rurais, no ramo da criação de gado de corte, de pequeno a grande porte. Os questionários foram aplicados in loco no Sindicato Rural de Ituiutaba-MG, abordando os dez produtores que ali se apresentavam no momento e posteriormente, o questionário foi aplicado a mais vinte produtores presentes em evento local de exposição agropecuária, também na cidade de Ituiutaba, cidade localizada na região do Triângulo Mineiro no Estado de Minas Gerais. Os produtores foram escolhidos de forma aleatória e a aplicação dos formulários ocorreu no mês de junho de 2013. 
Alguns dados foram elencados na pesquisa para efeitos meramente caracterizadores dos entrevistados e para auxiliar na interpretação de outros fatores. São eles: faixa etária e nível de escolaridade. Considerando o número de entrevistados em questão e para maior objetividade e compreensão, os dados são apresentados em frequência absoluta.

\section{RESULTADOS}

Com base na pesquisa realizada entre os produtores da área rural, buscou-se analisar o porte e a extensão de seu negócio, assim como as informações e os instrumentos gerenciais utilizados na tomada de decisão e no investimento da produção de gado de corte. Inicialmente caracterizaram-se os produtores rurais, ou seja, dos trinta (30) entrevistados, dezoito (18) deles estão em uma faixa etária entre 35 a 50 anos e doze (12) estão acima de 50 anos, todos do sexo masculino. Resultado diferente de Barella, Nascimento e Sobral (2016) que apresentaram pesquisa semelhante e obtiveram $80 \%$ dos respondentes do sexo masculino e $55 \%$ dos pesquisados acima de 51 anos.

Nota-se, Tabela 1, que grande parte dos entrevistados criam gado de corte em área de sua propriedade particular e alguns utilizam uma outra área arrendada além da propriedade particular. Acredita-se que estes utilizam esta área extra, pela necessidade de expandir seus negócios, em virtude da pouca disponibilidade de pasto em sua propriedade, decidindo portanto, ampliar o negócio e responsabilizar-se por maiores custos no arrendamento/aluguel de outras propriedades para atender sua demanda.

Tabela 1 - Tipo de propriedade utilizada para criação do gado de corte

\begin{tabular}{ccccc}
\hline Alugada/arrendada & Propriedade particular & Cedida sem ônus & Parceria/Meeiro & Propriedade com sócio \\
\hline 14 & 16 & 0 & 0 & 0
\end{tabular}

Fonte: Elaborada pelos autores.

Dos dezessseis entrevistados que responderam utilizar apenas de sua propriedade particular para o desenvolvimento de sua atividade rural, oito deles adquiriram a propriedade rural, em parte, por meio de herança e outra parte por rendimentos advindos de suas atividades, ou seja, ampliando seu patrimônio, não estagnando apenas no que herdara de seus familiares (Tabela 2). Apenas quatro $(25 \%)$ continuam com patrimônio decorrente da herança familiar.

Tabela 2 - Origem do patrimônio existente

\begin{tabular}{cccccc}
\hline Herança & $\begin{array}{c}\text { Herança e } \\
\text { renda }\end{array}$ & $\begin{array}{c}\text { Herança e } \\
\text { financiamento }\end{array}$ & $\begin{array}{c}\text { Recursos } \\
\text { próprios }\end{array}$ & $\begin{array}{c}\text { Recursos financiados } \\
\text { parcialmente }\end{array}$ & $\begin{array}{c}\text { Recursos financia- } \\
\text { dos (total) }\end{array}$ \\
\hline 4 & 8 & 0 & 4 & 0 & 0 \\
\hline
\end{tabular}

Fonte: Elaborada pelos autores.

A Tabela 3 mostra que a maioria dos entrevistados possui mais de 20 anos de experiência no ramo de gado de corte mas, em contraponto, nota-se que mesmo com o tempo de experiência apenas nove produtores conseguiram ampliar seu plantel em mais de 500 cabeças de gado (Tabela 4).

Tabela 3 - Tempo de atuação no ramo de negócio

\begin{tabular}{cccccc}
\hline Até $\mathbf{1}$ ano & $\mathbf{1}$ a $\mathbf{5}$ anos & $\mathbf{5}$ a $\mathbf{1 0}$ anos & $\mathbf{1 0}$ a $\mathbf{1 5}$ anos & $\mathbf{1 5}$ a $\mathbf{2 0}$ anos & Mais de 20 anos \\
\hline 0 & 0 & 0 & 0 & 6 & 24 \\
\hline
\end{tabular}

Fonte: Elaborada pelos autores.

Portanto, percebe-se que há uma lacuna na tomada de decisão no que se refere aos investimentos ou no controle dos processos e das atividades inerentes à atividade. Kitagawa e Sornberger (2010) constataram que os criadores de gado de corte de médio porte do município de 
Marcelândia/MT não mantêm nenhum tipo de planejamento e controle sobre as suas atividades. Cabe analisar as informações gerenciais utilizadas para a ampliação do negócio, assim como o uso adequado e o controle de custos e de investimentos para verificar a causa do pequeno crescimento do rebanho.

Tabela 4 - Número de cabeças de gado para corte

\begin{tabular}{ccccc}
\hline Até $\mathbf{5 0}$ cabeças & $\mathbf{5 0}$ a $\mathbf{1 0 0}$ cab. & $\mathbf{1 0 0}$ a $\mathbf{3 0 0}$ cab. & $\mathbf{3 0 0}$ a $\mathbf{5 0 0}$ cab. & Acima de $\mathbf{5 0 0}$ cab. \\
\hline 0 & 3 & 12 & 6 & 9 \\
\hline
\end{tabular}

Fonte: Elaborada pelos autores.

Como relatado anteriormente, grande parte dos entrevistados apresentaram uma experiência de mais de vinte anos de atuação no ramo da pecuária de corte e esperava-se que a maioria deles tivessem condições efetivas de tomar decisões mais precisas e planejadas, mas o que se observa é que apenas três entrevistados possuem um faturamento líquido anual entre $\mathrm{R} \$$ 200.000,00 e R \$300.000,00 (Tabela 5). Considerando o número elevado de cabeças de gado dos produtores (a maioria tem acima de 100 cabeças) o faturamento líquido anual é baixo. Pode-se inferir a falta ou o pouco uso de ferramentes e de controle gerencial no que tange a faturamente e lucratividade. Assim, o uso das informações contábeis além de mostrar a margem da atividade e a lucratividade, ajuda a controlar os custos e evidencia eventuais restrições.

Tabela 5 - Faturamento Líquido Anual (R\$)

\begin{tabular}{ccccccc}
\hline Menos de & $\mathbf{1 0 . 0 0 0 , 0 0}$ a & $\mathbf{5 0 . 0 0 0 , 0 0}$ a & $\mathbf{1 0 0 . 0 0 0 , 0 0}$ a & $\mathbf{2 0 0 . 0 0 0 , 0 0}$ a & $\mathbf{3 0 0 . 0 0 0 , 0 0}$ a & Acima de \\
$\mathbf{1 0 . 0 0 0 , 0 0}$ & $\mathbf{5 0 . 0 0 0 , 0 0}$ & $\mathbf{1 0 0 . 0 0 0 , 0 0}$ & $\mathbf{2 0 0 . 0 0 0 , 0 0}$ & $\mathbf{3 0 0 . 0 0 0 , 0 0}$ & $\mathbf{4 0 0 . 0 0 0 , 0 0}$ & $\mathbf{4 0 0 . 0 0 0 , 0 0}$ \\
\hline 0 & 3 & 9 & 15 & 3 & 0 & 0 \\
\hline
\end{tabular}

Fonte: Elaborada pelos autores.

Dos trinta entrevistados, vinte e quatro produtores responderam que atuam também em outra atividade rural (Tabela 6). Ao analisar detalhadamente, destes vinte e quatro, quinze possuem uma área maior que 100 hectares para desenvolverem possivelmente duas ou mais atividades rurais. Apenas seis entrevistados, mesmo com uma área maior que 100 hectares, atuam somente com gado de corte, sem necessidade de diversificação na produção. No trabalho de Barella, Nascimento e Sobral (2016) 40\% dos produtores de gado apresentam propriedades entre 1251 e 1750 hectares. Talvez em decorrência dessas grandes áreas, 65\% do rebanho dos respondentes concentrava-se entre 1501 e 2500 cabeças de gado, valores bastante discrepantes em relação à pesquisa no município de Ituiutaba-MG (Tabela 4).

\begin{tabular}{lcc}
\multicolumn{2}{c}{ Tabela 6 - Área utilizada para o gado de corte x outras atividades rurais } \\
\hline \multicolumn{2}{c}{ Área utilizada para gado de } & \multicolumn{2}{c}{ Possui outra atividade rural? } \\
\cline { 2 - 3 } \multicolumn{1}{c}{ corte } & Sim & Não \\
\hline Menos de 10 hectares (ha) & 0 & 0 \\
10 a 20ha & 3 & 0 \\
20 a 50ha & 6 & 0 \\
50 a 100ha & 0 & 0 \\
Mais de 100ha & 15 & 6 \\
\hline
\end{tabular}

Fonte: Elaborada pelos autores.

Apesar de grande parte dos produtores possuírem outra atividade tem-se que a principal atividade "extra" é o gado de leite (Tabela 7), ou seja, uma atividade afim. Em seguida destaca-se a agricultura e a suinocultura. Na agricultura, uma relevante produção de cana-de-açúcar e sorgo, é 
utilizada para a alimentação do gado de corte, portanto, com uma relação direta entre as duas atividades, uma servindo como suporte a outra, inclusive com suporte gerencial para decisões quanto ao índice de produção de insumos para o gado de corte, necessitando de informações precisas para a estocagem. As demais atividades se justificam até mesmo pela caracterização da região e as condições favoráveis para tal investimento.

Tabela 7 - Outra atividade desenvolvida

\begin{tabular}{cccccc}
\hline Agricultura & Equinocultura & Gado leiteiro & Suinocultura & Avicultura & Outros \\
\hline 5 & 0 & 11 & 5 & 0 & 3 \\
\hline
\end{tabular}

Fonte: Elaborada pelos autores.

Na Tabela 8, viu-se que o controle da administração do negócio fica centralizado no proprietário, e o gerenciamento fica sob o seu comando de uma forma em geral. Esse resultado reforça Viana, Costa e Santos (2014), que constatam que a contabilidade rural no Brasil ainda se desenvolve dentro de critérios bastante tradicionais. Essa característica não é encontrada apenas em pequenas propriedades rurais, mas também entre as médias e grandes propriedades rurais.

Tabela 8 - Responsáveis por anotações informais de controle e administração do negócio

\begin{tabular}{cccc}
\hline Empregado & Proprietário & Família do proprietário & Outros \\
\hline 3 & 24 & 3 & 0 \\
\hline
\end{tabular}

Fonte: Elaborada pelos autores.

Considerando a Tabela 9, observa-se que a maioria dos entrevistados utilizam instrumentos informais e ainda arcáicos em relação aos instrumentos de controle do negócio (informalidade e as anotações em caderno). Resultado que pode ser confirmado por Marion (1996, p. 19), o qual cita que "administrar uma atividade agropecuária requer ampla abrangência de informações em termos de desempenho físico e financeiro. Algumas vezes, entretanto, muitas das informações necessárias são registradas apenas na memória de quem administra ou em anotações informais." Dezoito deles possuem contador próprio para sua empresa rural.

Tabela 9 - Instrumentos utilizados no controle do negócio

\begin{tabular}{cccccc}
\hline Informal & Anota em caderno & Possui contador próprio & Planilha eletrônica & Sistema informatizado & Outros \\
\hline 3 & 24 & 18 & 0 & 0 & 0 \\
\hline
\end{tabular}

Fonte: Elaborada pelos autores.

A Tabela 10 apresenta uma distribuição relativamente considerável entre quatro fatores considerados como relevantes para gerenciar o negócio de gado de corte: controle de estoques, balanço patrimonial, custo mensal da fazenda e a margem de lucro por animal. Possivelmente, como apresentado anteriormente, muitos deles possuem estas informações de modo informal, mas cabe saber se estas estão sendo relevantes para o gerenciamento adequado do negócio.

A contabilidade mostra a posição financeira em determinada data, evidencia onde os custos e as despesas são consumidos, subsidiando o processo de planejamento. No estudo de Barella, Nascimento e Sobral (2016) o aspecto positivo da utilização da informação contábil no setor pecuário é o balanço patrimonial para $27,11 \%$ dos entrevistados.

Na pesquisa de Souza (2004), apesar de a informação contábil ser utilizada parcialmente no processo de tomada de decisão, os itens de maior relevância foram o inventário (95\%), relatório de receitas e despesas $(85 \%)$, relatório de produção $(82 \%)$, relatório de custos $(80 \%)$, fluxo de caixa $(42,5 \%)$, balanço patrimonial $(22,5 \%)$ e demonstração do resultado do exercício (20\%). 
Tabela 10 - Fatores com informações relevantes e utilizadas efetivamente no gerenciamento do negócio

\begin{tabular}{cccccc}
\hline $\begin{array}{c}\text { Custo por oportuni- } \\
\text { dade do animal }\end{array}$ & $\begin{array}{c}\text { Controle de esto- } \\
\text { ques }\end{array}$ & $\begin{array}{c}\text { Balanço Patri- } \\
\text { monial (anual) }\end{array}$ & $\begin{array}{c}\text { Custo mensal } \\
\text { da fazenda }\end{array}$ & $\begin{array}{c}\text { Margem de lucro } \\
\text { por animal/produto }\end{array}$ & Nenhuma \\
\hline 0 & 12 & 15 & 9 & 6 & 0
\end{tabular}

Fonte: Elaborada pelos autores.

Por mais que se busquem informações gerenciais, sejam informais ou não, a grande preocupação dos produtores ainda está em obter informações somente para atender o fisco/imposto de renda (Tabela 11). Semelhante a Pereira, Oliveira e Barbalho (2007, p. 54) onde "os relatórios produzidos pelo setor de contabilidade só são utilizados para responder questões fiscais e tributárias e não sobre o negócio como um todo". Percebe-se que os produtores não conseguem identificar as vantagens da utilização das informações gerenciais para a sua atividade, visto que poucos consideram o controle e a redução de custos, as informações para a tomada de decisão e o planejamento (Tabela 11).

Resultado similar ao de Barella, Nascimento e Sobral (2016) que observaram que $40 \%$ dos produtores de gado da cidade de Nova Andradina - MS raramente utilizavam relatórios contábeis na sua atividade. Destaca-se também que o uso de indicadores de controle e desempenho, tais como índice de natalidade ou mortalidade, taxa de crescimento do rebanho, etc., também não eram solicitados pelos produtores aos seus contadores. O plantel era valorado pelo valor de mercado, não sendo adotado nenhum sistema de custeio.

Tabela 11 - Vantagens das informações gerenciais e contábeis para o negócio

\begin{tabular}{cccccc}
\hline $\begin{array}{c}\text { Controle dos } \\
\text { custos de } \\
\text { produção }\end{array}$ & $\begin{array}{c}\text { Informações preci- } \\
\text { sas para tomada } \\
\text { de decisão }\end{array}$ & $\begin{array}{c}\text { Redução de } \\
\text { custos }\end{array}$ & $\begin{array}{c}\text { Planejamento } \\
\text { com base na } \\
\text { lucratividade }\end{array}$ & $\begin{array}{c}\text { Possibilidade de } \\
\text { novos investi- } \\
\text { mentos }\end{array}$ & $\begin{array}{c}\text { Informações para } \\
\text { o fisco }\end{array}$ \\
\hline 3 & 9 & 6 & 0 & 9 & 24 \\
\hline
\end{tabular}

Fonte: Elaborada pelos autores.

De acordo com os produtores, o que os motiva a aumentar a criação de gado é se manter na atividade, aumentar a receita da família e ter uma alternativa a mais de renda (Tabela 12). Dados aparentemente contraditórios ao apresentado na Tabela 11, pois pretendem melhorar as receitas e os lucros, mas não identificam vantagens nas informações gerenciais. Nessa sequência, Lima (2006) relata que o grau de importância que os gestores dão à informação contábil e o tipo de informação que utilizam no processo decisório não indicam que eles utilizam a contabilidade em nível gerencial.

Tabela 12 - Motivos que levam os produtores a buscar o aumento na criação de gado de corte

\begin{tabular}{cccccc}
\hline $\begin{array}{c}\text { Melhoria na } \\
\text { atividade }\end{array}$ & $\begin{array}{c}\text { Necessidade para se } \\
\text { manter na atividade }\end{array}$ & $\begin{array}{c}\text { Aumentar a receita da fa- } \\
\text { mília/alternativa de renda }\end{array}$ & $\begin{array}{c}\text { Taxas de ju- } \\
\text { ros atraentes }\end{array}$ & $\begin{array}{c}\text { Sobra de } \\
\text { recursos }\end{array}$ & $\begin{array}{c}\text { Crescimento natu- } \\
\text { ral da produção }\end{array}$ \\
\hline 3 & 18 & 12 & 0 & 0 & 6 \\
\hline
\end{tabular}

Fonte: Elaborada pelos autores.

Para a maioria dos produtores, o lucro obtido com a atividade é utilizado na ampliação do plantel e na melhoria das pastagens para dar sequência ao processo produtivo (Tabela 13). Seria conveniente utilizar-se da contabilidade para verificar a rentabilidade do investimento.

Tabela 13 - Uso do lucro originário da pecuária de corte

\begin{tabular}{ccccccc}
\hline $\begin{array}{c}\text { Melhoria das } \\
\text { pastagens }\end{array}$ & $\begin{array}{c}\text { Ampliação } \\
\text { do plantel }\end{array}$ & $\begin{array}{c}\text { Ações na } \\
\text { bolsa de } \\
\text { valores }\end{array}$ & $\begin{array}{c}\text { Poupança ou } \\
\text { rendimentos } \\
\text { bancários }\end{array}$ & $\begin{array}{c}\text { Parcialmente em } \\
\text { investimentos e la- } \\
\text { zer com a família }\end{array}$ & $\begin{array}{c}\text { Compra de } \\
\text { imóveis } \\
\text { rurais }\end{array}$ & $\begin{array}{c}\text { Compra de } \\
\text { imóveis } \\
\text { urbanos }\end{array}$ \\
\hline 18 & 24 & 0 & 3 & 3 & 3 & 0 \\
\hline
\end{tabular}

Fonte: Elaborada pelos autores. 
Constata-se que a contabilidade e os instrumentos contábeis ainda são praticamente irrisórios para a tomada de decisão dado que apenas nove dos entrevistados utilizam como ferramentas a análise das receitas/custos e lucros, com enfoque maior nos indicadores econômicos (Tabela 14). Resultado até certo ponto esperado, em decorrência dos instrumentos utilizados no controle do negócio (Tabela 9).

Salienta-se que no estudo de Barella, Nascimento e Sobral (2016) apenas 25\% dos entrevistados utilizam os relatórios contábeis para planejamento e apenas $30 \%$ consideram o relatório de custos e de despesas/receitas como benefício da informação contábil.

Tabela 14 - Ferramentas utilizadas na tomada de decisão

\begin{tabular}{ccccccc}
\hline $\begin{array}{c}\text { Indicadores } \\
\text { de produtivi- } \\
\text { dade }\end{array}$ & $\begin{array}{c}\text { Indicado- } \\
\text { res econô- } \\
\text { micos }\end{array}$ & $\begin{array}{c}\text { Indicadores de } \\
\text { lucratividade }\end{array}$ & $\begin{array}{c}\text { Declaração } \\
\text { do Imposto } \\
\text { de Renda }\end{array}$ & $\begin{array}{c}\text { Análise das recei- } \\
\text { tas/custos/lucro }\end{array}$ & $\begin{array}{c}\text { Análise de } \\
\text { possíveis in- } \\
\text { vestimentos }\end{array}$ & $\begin{array}{c}\text { Indicadores de } \\
\text { liquidez e ren- } \\
\text { tabilidade }\end{array}$ \\
\hline 0 & 18 & 0 & 6 & 9 & 0 & 0 \\
\hline
\end{tabular}

Fonte: Elaborada pelos autores.

Infere-se que falta informação, maior sensibilização ou até mesmo qualificação/treinamento da classe produtora em questão de gerenciamento, visto que metade dos produtores entrevistados ainda não consideram as informações contábeis suficientes para a tomada de decisão (Tabela 15). Resultado parecido ao de Barella, Nascimento e Sobral (2016) onde apenas 15\% consideram a informação contábil importante.

No entanto, os produtores deveriam considerar Miranda e Silva (2002, p. 137) ao afirmarem que "gerenciar uma organização é definir a prioridade com que seus recursos (físicos, financeiros, humanos, tecnológicos, etc.) serão consumidos, visando a alcançar os objetivos predeterminados".

Tabela 15 - As Ferramentas e as informações contábeis são suficientes para a tomada de decisão?

\begin{tabular}{cc}
\hline Sim & Não \\
\hline 15 & 15 \\
\hline
\end{tabular}

Fonte: Elaborada pelos autores.

Assim como na Tabela 8, onde a maioria das anotações diárias são feitas pelo próprio produtor, vinte e sete deles também são responsáveis pela previsão de pagamentos e recebimentos, o que leva novamente à centralização de poder e de tomada de decisão (Tabela 16).

Os produtores rurais atuam na maioria das vezes como proprietário e também como gestor, deixando em alguns casos de observar os princípios e normas contábeis da entidade, misturando os gastos da família e os da empresa, o que pode prejudicar o resultado esperado de sua produção (MARION, 1996).

Tabela 16 - Responsável pela previsão de pagamento de custos, despesas, recebimento de lucros e contas a receber

\begin{tabular}{ccccc}
\hline Produtor & Gerente/Administrador & Escritório de Contabilidade & Outros & Não é feita previsão \\
\hline 27 & 0 & 3 & 0 & 0 \\
\hline
\end{tabular}

Fonte: Elaborada pelos autores.

A Tabela 17, confirma as respostas anteriores, pois o principal motivo que faz o produtor procurar um escritório de contabilidade são as questões relativas ao fisco/imposto de renda. Questões relativas a controles, seja de forma patrimonial, de contas da propriedade, de pagamentos e recebimentos raramente são considerados. 
Esse ponto, confirma Barella, Nascimento e Sobral (2016), onde $50 \%$ dos produtores utilizam das informações de imposto renda como principal serviço utilizado da contabilidade. Estes autores ainda destacam que para $40 \%$ dos entrevistados a principal mudança necessária para utilização das informações contábeis na atividade pecuária é a clareza na informação. Todavia, na visão dos produtores, o principal fator que dificulta o uso da informação contábil é o alto custo do contador (45\%).

Tabela 17 - Motivo em utilizar os serviços prestados por um escritório de contabilidade

\begin{tabular}{cccc}
\hline Fisco/Imposto de Renda & $\begin{array}{c}\text { Exigência do banco para } \\
\text { refinanciamento }\end{array}$ & $\begin{array}{c}\text { Controle das contas da } \\
\text { propriedade }\end{array}$ & $\begin{array}{c}\text { Controles para paga- } \\
\text { mento/recebimentos }\end{array}$ \\
\hline 30 & 0 & 3 & 3 \\
\hline Controle patrimonial & $\begin{array}{c}\text { Controle gerencial/ } \\
\text { Controladoria }\end{array}$ & Gerenciamento de custos & Não utiliza \\
\hline 3 & 0 & 0 & 0
\end{tabular}

Fonte: Elaborada pelos autores.

Estes resultados demonstram de maneira geral o que concluiu Souza (2004) sobre a atividade pecuária do Rio Grande do Norte, ou seja, as informações contábeis não são utilizadas plenamente para tomada de decisão econômico-financeira dos gestores do setor pecuário. Lima (2006) também conclui nesse sentido, uma vez que as informações fornecidas pela contabilidade são consideradas importantes, porém são pouco utilizadas no processo de gestão.

\section{CONSIDERAÇÕES FINAIS}

O presente estudo teve como objetivo geral verificar o uso de ferramentas e informações gerenciais pelo produtor rural, no ramo de gado de corte, identificando os fatores motivadores para o direcionamento e tomada de decisão em seu negócio. Após informações levantadas por meio da aplicação de questionário com trinta produtores rurais, infere-se que o produtor rural de gado de corte comporta-se em sua maioria na busca por benefícios que possam manter sua atividade produtiva e dar subsídios para manutenção dos fatores de produção referente ao capital e a extensão da terra, seja arrendada ou de propriedade particular.

Além disso, o uso das informações contábeis e gerenciais, são bem restritos, ficando especificamente para o registro de atividades e produtividade junto ao fisco/imposto de renda e o controle patrimonial, sendo as informações detalhadas informalmente, sem nenhum controle prévio ou planejamento da atividade, seja de um produtor de pequeno, médio ou grande porte.

Este estudo confirma os resultados apresentados por Marion (1996), Vestena et al. (2011) e Hofer et al. (2011) que pesquisaram o agronegócio como um todo, destacando que os serviços de contabilidade são utilizados por todos os entrevistados, mas especificamente para o fisco/imposto de renda, com uma leve tendência do produtor de grande porte buscar o escritório de contabilidade para outras funcionalidades. É contraditório quando os criadores relatam que utilizam de informações contábeis e gerenciais para tomada de decisão, principalmente no que se refere à manutenção da atividade, controle gerencial e investimento na ampliação do plantel, porque na realidade estas informações são advindas de um controle informal, a não ser o balanço patrimonial anual e a declaração de renda elaborada pelo escritório de contabilidade.

Percebe-se que há uma grande lacuna entre a contabilidade gerencial rural e o produtor rural, devendo ser preenchida por uma maior sensibilização da classe produtora, demonstrando a relevância da contabilidade gerencial e suas informações emitidas, permitindo uma tomada de decisão com um alto grau de assertividade para otimizar os resultados, em conformidade com a disponibilidade da informação contábil. Esse tipo de conhecimento acerca do ambiente organizacional, 
sobretudo as ameaças e oportunidades, os pontos fortes e fracos, é a exigência mínima que se impõe aos gestores de qualquer empresa.

O estudo em questão demonstrou que a contabilidade rural é um processo sistemático que ainda está com uso restrito e que sua teoria deve ser apresentada de uma forma a sensibilizar os produtores rurais a utilizá-la com mais ênfase para o desenvolvimento de suas atividades rurais, novos investimentos, assim como para a manutenção de seu negócio no mercado.

Uma contribuição relevante para dar seguimento a novos estudos científicos no que se refere à contabilidade rural e, mais especificamente, à contabilidade da pecuária, pois as propriedades rurais nada mais são do que empresas rurais e devem ser levadas com a mesma seriedade e planejamento que as demais empresas. Observaram-se, ainda, certas limitações quanto ao objeto de pesquisa, visto que os produtores rurais se sentem inibidos e receosos quanto à divulgação de informações detalhadas para o campo de pesquisa, em virtude de dados mais sigilosos.

Para futuros estudos, seguem recomendações quanto à realização de pesquisas restritas com produtores rurais de grande porte, para avaliar se os comportamentos dos mesmos alteram quanto ao uso de ferramentas e informações gerenciais, visto que neste estudo observou-se uma tendência a valorizar a contabilidade e a buscar informações gerenciais a partir do momento em que a empresa rural passa a ter um faturamento maior e uma área de produção relativamente extensa.

\section{REFERÊNCIAS}

ALI, J.; KUMAR, S. Information and Communication Technologies (ICTs) and farmers'decisionmarking across the agricultural suplly chain. International Journal of Information Management, v. 31, n. 2, p. 149-159, 2011.

BARNES, A. P. et al. Farmer decision-making and risk perceptions towards outwintering cattle. Journal of Environmental Management, v. 129, p. 9-17, nov.2013.

BARELLA, L. A.; NASCIMENTO, L. S.; SOBRAL, F. A utilização da contabilidade como ferramenta de apoio aos pecuaristas no município de Alta Floresta Mato Grosso no ano de 2016. Revista Internacional de Ciências, v. 6, n. 1, p. 89-108, jan./jun. 2016.

BATALHA, M. O. (coord.). Gestão Agroindustrial. 3. ed. São Paulo: Atlas, 2008.

BEUREN, I. M. Como elaborar trabalhos monográficos em contabilidade: teoria e prática. 3. ed. São Paulo: Atlas, 2012.

CALLADO, A. A. C., CALLADO, A. L. C. Mensuração e controle de custos: um estudo empírico em empresas agroindustriais. Revista Eletrônica Sistemas \& Gestão, v. 1, n. 2, p. 132-141, mai./ago., 2006. Disponível em: www.latec.com.br. Acesso em: 02 maio 2013.

CALSINA, S. O. Um nuevo paradigma de agronegócio sostenible: análisis e propuesta teórica. Agroalimentaria, v. 13, n. 35, p. 31-42, jul./dic., 2012.

CARVALHO, F. M.; FIÚZA, M. A.; LOPES, M. A. Determinação de custos como ação de competitividade: estudo de um caso na avicultura de corte. Revista Ciência e Agrotecnologia, v. 32, n. 3, p. 908913, mai./jun. 2008. 
CONNOLLY, A. J.; CONNOLLY, K. P.; LYONS, M. A Seismic change: land control in Africa. Is this a wake-up call for agribusiness?. International Food and Agrobusiness Management Review, v. 15, n. 2, p. $171-177,2012$.

CONSELHO NACIONAL DA PECUÁRIA DE CORTE - CNPC. PIB do Agronegócio cresce 2,99\% em 2013, puxado pelo setor primário. Disponível em: http://www.cnpc.org.br/news1.php?ID=6252. Acesso em: 18 jul. 2013.

CONTINI, E. Dinamismo do agronegócio brasileiro. Agronline.com.br. Disponível em: http://www.agronline.com.br/artigos/artigo.php?id=22. Acesso em: 24 maio 2013.

COOK, M. L.; CHADDAD, F. R. Agroindustrialization of the global agrifood economy: bridging development economics and agribusiness research. Agricultural Economics, v. 23, p. 207-218, 2000.

CREPALDI. S. A. Contabilidade Rural: uma abordagem decisorial. 7. ed. Revista atualizada e ampliada. São Paulo: Atlas, 2012.

DAVIS, J. H.; GOLDBERG, R. A. A concept of agribusiness. New York: Alpine, 1957.

FRANCISCHETTI JUNIOR, S. C., ZANCHET, A. Perfil contábil-administrativo dos produtores rurais e a demanda por informações contábeis. Ciências Sociais Aplicadas em Revista, v. 6, n. 11, 2006. Disponível em: www.unioeste.br. Acesso em: 25 maio 2013.

GIL, A. C. Métodos e técnicas em pesquisa social. 5. ed. São Paulo: Atlas, 1999.

HENDRIKSEN, E. S.; VAN BREDA, M. F. Teoria da Contabilidade. 5. ed. São Paulo: Atlas, 1999.

HOFER, E. et al. A Relevância do Controle Contábil para o Desenvolvimento do Agronegócio em Pequenas e Médias Propriedades Rurais. Revista de Contabilidade e Controladoria, v. 3, n. 1, p. 27-42, jan./abr. 2011.

HORNGREN, C. T.; SUNDEM, G. L.; STRATTON, W. O. Contabilidade Gerencial. 12. ed. São Paulo: Pearson/Prentice Hall, 2004.

HUTCHINGS, T. R.; NORDBLOM, T. L. A financial analysis of the effect of the mix of crop and sheep enterprises on the risk profile of dryland farms in south-eastern Australia. African Journal of Business Management, v. 8, n. 1, p. 19 - 42. 2011.

IUDÍCIBUS, S. Contabilidade Gerencial. 6. ed. São Paulo: Atlas, 2006.

KITAGAWA, A. A. V.; SORNBERGER, G. P. Diagnóstico sobre a utilização da contabilidade na gestão das propriedades pecuárias de médio porte no município de Marcelândia/MT. Revista Contabilidade E Amazônia, v. 3, n. 1, p. 61-76, jan./dez. 2010.

KORUTARO, B.; BIEKPE, N. Effect of business regulation on investment in emerging market economies. Review of Development Finance, v. 3, n. 1, p. 41-50, 2013. 
LEMES, S. Contabilidade na agropecuária. In: MARION, J. C. (Coord.). Contabilidade e Controladoria em Agribusiness. São Paulo: Atlas, 1996, p. 30-42.

LIMA, M. M. S. de. O uso da O uso da informação contábil no setor sucroalcooleiro: um estudo nas indústrias de Alagoas. 2006. 107 f. Dissertação (Mestrado em Mensuração Contábil) - Universidade Federal do Rio Grande do Norte, Natal, 2006.

MARION J. C. Contabilidade Rural: contabilidade agrícola, contabilidade da pecuária, imposto de renda pessoa jurídica. 8. ed. São Paulo: Atlas, 2006.

MARION J. C. Contabilidade e Controladoria em Agribusiness. São Paulo: Atlas, 1996.

MIRANDA, L. C.; SILVA, J. D. G. da. Medição de desempenho. In: SCHMIDT, P. (Org). Controladoria: agregando valor para a empresa. Porto Alegre: Bookman, 2002. p. 131-153.

PADOVEZE, C. L. Contabilidade Gerencial: um enfoque em sistema de informação contábil. 5. ed. São Paulo: Atlas, 2008.

PEREIRA, A. C.; OLIVEIRA, A. B. S.; BARBALHO, V. F. A utilização da informação contábil na gestão da pecuária bovina de corte: uma pesquisa empírica. Brazilian Business Review, v. 4, n. 1, p. 40-59, enero-abril, 2007.

RIBEIRO FILHO, J. F.; LOPES, J.; PEDERNEIRAS, M. Estudando Teoria da Contabilidade. São Paulo: Atlas, 2009.

RICHARDSON, R. J. Pesquisa social: métodos e técnicas. 3. ed. São Paulo: Atlas, 1999.

SÁ, A. L. Teoria da Contabilidade. 6. ed. São Paulo: Atlas, 2008.

SANTOS, G. J.; MARION, J. C. Administração de custos na agropecuária. São Paulo: Atlas, 1993.

SCHREISHEIM, C. A. et al. Improving construct measurement in management research: comments and a quantitative approach for assessing the theoretical content adequacy of paper-and-pencil survey-type instruments. Journal of Management, v. 19, n. 2, p. 385-417, 1993.

SOUZA, A. A. A. Custo de Produção do Gado de Corte Nelore de 12 a 36 meses: Estudo de Caso no Sítio União Caiabi Juína-MT. Monografia (Curso de Ciências Contábeis). Faculdade de Ciências Contábeis e Administração do Vale do Juruena, Juína, 2009.

SOUZA, D. C. de. A utilização da informação contábil na atividade pecuária do Estado do Rio Grande do Norte: Um enfoque nos demonstrativos gerados na tomada de decisão. 2004. 140 f. Dissertação (Mestrado em Ciências Contábeis) - Programa Multi-institucional e Inter-Regional de Pós-Graduação em Ciências Contábeis da Universidade de Brasília, Universidade Federal da Paraíba e Universidade Federal do Rio Grande do Norte, Natal, 2012.

THIOLLENT, M. Pesquisa-ação nas organizações. 1. ed. São Paulo: Atlas, 1997. 
VESTENA, F. S. et al. Análise da utilização de ferramentas contábeis e gerenciais de controle financeiro no ramo do agronegócio na região da Grande Dourados-MS. INGEPRO - Inovação, Gestão e Produção, v. 3, n. 1, p. 27-42, jan. 2011.

VIANA, C. M. S.; COSTA, J. M. E.; SANTOS, J. K. B. A importância da contabilidade rural na pecuária. Revista Saber Eletrônico On-line, n. 2, p. 5-23, ago./dez. 2014. Disponível em: < http://www.unifaj.edu.br/revistas/01_2015/artigo1.pdf> Acesso em 02/05/2016. 